\title{
Effect of Thickness of Indirect Restoration and Distance from the Light-Curing Unit Tip on the Hardness of a Dual-Cured Resin Cement
}

\author{
Andréia Bolzan de PAULA ${ }^{1}$ \\ Rubens Nisie TANGO ${ }^{2}$ \\ Mário Alexandre Coelho SINHORETI ${ }^{3}$ \\ Marcelo Corrêa ALVES ${ }^{1}$ \\ Regina M. PUPPIN-RONTANI ${ }^{4}$ \\ ${ }^{1}$ Piracicaba Dental School, State University of Campinas, Piracicaba, SP, Brazil \\ ${ }^{2}$ Department of Dental Materials and Prosthodontics, São José dos Campos Dental School, \\ São Paulo State University, São José dos Campos, SP, Brazil \\ ${ }^{3}$ Department of Restorative Dentistry, Piracicaba Dental School, State University of Campinas, Piracicaba, SP, Brazil \\ ${ }^{4}$ Department of Pediatric Dentistry, Piracicaba Dental School, State University of Campinas, Piracicaba, SP, Brazil
}

\begin{abstract}
This study evaluated the Knoop hardness and polymerization depth of a dual-cured resin cement, light-activated at different distances through different thicknesses of composite resin. One bovine incisor was embedded in resin and its buccal surface was flattened. Dentin was covered with PVC film where a mold (0.8-mm-thick and $5 \mathrm{~mm}$ diameter) was filled with cement and covered with another PVC film. Light curing (40 s) was carried out through resin discs $(2,3,4$ or $5 \mathrm{~mm}$ ) with a halogen light positioned $0,1,2$ or $3 \mathrm{~mm}$ from the resin surface. After storage, specimens were sectioned for hardness measurements (top, center, and bottom). Data were subjected to split-plot ANOVA and Tukey's test $(\alpha=0.05)$. The increase in resin disc thickness decreased cement hardness. The increase in the distance of the light-curing tip decreased hardness at the top region. Specimens showed the lowest hardness values at the bottom, and the highest at the center. Resin cement hardness was influenced by the thickness of the indirect restoration and by the distance between the light-curing unit tip and the resin cement surface.
\end{abstract}

Key Words: hardness, dental materials, resin cements, composite resin.

\section{INTRODUCTION}

The success of indirect esthetic restorations depends mainly on the luting agent, which should guarantee an effective bonding between the restoration and the dental substrate, preserving the marginal seal(1). Despite the variety of commercially available cements, there is no ideal cement for all clinical situations. Therefore, the choice of the luting agent must rely on the physical and biological properties as well as the handling characteristics of this material associated with the characteristics of the prosthetic restoration (2).

In an attempt to combine the desirable properties of self- and light-activated resin cements, dual-cured cement was developed to allow the clinician to control the polymerization time and for proper polymerization at deep areas where light is strongly attenuated due to the distance from the light-curing unit tip. However, in some clinical situations, some factors such as light intensity, exposure time, thickness, composition, shade and opacity of the indirect restorative material can affect the amount of energy reaching the cement (3).

Studies have demonstrated that the distance from the top of the highest cusp to the cavity floor can reach $8 \mathrm{~mm}$ at deep cavities $(4,5)$, so the light intensity reaching the deepest region can be strongly attenuated. As a consequence, lower degree of conversion is expected from resin cements when the energy is lower than that required for a proper resin cement polymerization, leading to postoperative sensitivity, staining, marginal

Correspondence: Profa. Dra. Regina Maria Puppin-Rontani, Departmento de Odontopediatria, Faculdade de Odontologia de Piracicaba, UNICAMP, Avenida Limeira, 901, Areião, 13414-903 Piracicaba, SP, Brasil. Tel: +55-19-2106-5286. Fax: +55-19-2106-5218. email: rmpuppin@fop.unicamp.br 
breaking, poor adhesion between the tooth and the indirect restoration (6), microleakage, secondary caries, and changes in some cement mechanical properties. The degree of conversion depends on the energy supplied during light activation, and can be characterized as the product of light intensity and exposure time (7). The hardness test is a simple and reliable method commonly used as indicative of the degree of conversion of resin cements.

Studies have shown that an increase in the thickness of indirect restorative materials can decrease the hardness of the luting agent $(8,9)$. El-Badrawy and El-Mowafy (10) evaluated the effect of ceramic and resin composite thickness on hardness of 7 dual-cured resin cements for indirect restorations and observed a similar and gradual trend to a reduction of cement Knoop hardness with increase in the thickness of the restorative material. These results were attributed to the light attenuation caused by the increase in opacity and thickness.

The distance between the light-curing unit tip and the uncured resin material can be another factor affecting the monomer conversion and mechanical properties of resin composites. Caldas et al. (11) evaluated the influence of the distance between the light-curing unit tip and Filtek Z250 resin composite on Knoop hardness using 3 different light-curing units. The authors observed that the increase in such distance leads to a decrease in resin hardness and they attributed this result to the lower degree of conversion due to poor light intensity delivered to the composite. The aim of this study was to evaluate the influence of different thicknesses of composite indirect restorations and different light-curing unit tip distances on the Knoop hardness of Rely X ARC dualcured resin cement.

\section{MATERIAL AND METHODS}

\section{Preparation of Resin Discs}

Four pre-cured discs of Filtek Z250 composite resin, shade C4 (3M/ESPE, St. Paul, MN, USA) with 2, 3, 4 and $5 \mathrm{~mm}$ in thickness and $8 \mathrm{~mm}$ in diameter were created to simulate composite indirect restorations with different thicknesses. A rubber mold was filled with Filtek Z250 over a polyester strip (Polidental Ind. and Com., São Paulo, SP, Brazil) and a glass slab with $4 \mathrm{~mm}$ in thickness. Light curing of each 2-mm-thick increment was done with a conventional quartz tungsten halogen light-curing unit with power density of $800 \mathrm{~mW} / \mathrm{cm}^{2}$ (Elipar Trilight; 3M/ESPE) for $40 \mathrm{~s}$. Light intensity was checked with a handheld digital radiometer (Dental Hilux Curing Light Meter, Dental Benlioglu, Inc., Ankara, Turkey) before photoactivation. Prior to light curing of the last increment of each disc, the material was covered with a polyester strip, originating flat surfaces without resin excesses. The polymerized discs were stored dry at room temperature until the moment of use.

\section{Substrate Preparation}

To simulate the cementation of indirect restoration, a bovine tooth had its root sectioned and the incisal and proximal surfaces of the crown were ground sequentially under water cooling in a polishing machine (APL-4; Arotec, Cotia, SP, Brazil) with 120- and 200-grit silicon carbide papers (Carborundum, Saint-Gobain, Recife, PE, Brazil). The tooth was embedded in polystyrene resin in a PVC mold (Piraglass, Piracicaba, SP, Brazil) and, after resin polymerization, the buccal surface was wet-ground flat sequentially with 200-, 400- and 600grit $\mathrm{SiC}$ paper (12).

\section{Specimen Preparation}

The material used in the specimen preparation was the dual-cured resin cement Rely X ARC (3M/ ESPE). The specimens were photoactivated for $40 \mathrm{~s}$ each using the same light-curing unit. The irradiance of the light-curing unit was measured with a digital handheld radiometer (Dental Hilux Curing Light; Dental Benlioglu, Inc.). Rubber molds (5 mm diameter x $0.8 \mathrm{~mm}$ thick) were used as matrix for resin cement specimens. These molds were positioned on the prepared bovine tooth previously covered with a PVC film (Goodyear do Brasil Produtos de Borracha Ltda, São Paulo, SP, Brazil). After mixing according to the manufacturer's instructions, the cement was inserted in the mold and covered with another PVC film. The pre-cured composite discs with different thicknesses were then seated and the resin cement was light-activated through the indirect resin restoration using 4 different distances obtained with standardized resin acrylic spacers ( $8 \mathrm{~mm}$ diameter): 0 (direct contact with composite surface), 1, 2 and $3 \mathrm{~mm}$ from the composite surface (Fig. 1). The test groups were determined by the combination of different thicknesses of composite resin discs and the distance between the light-curing unit tip and the surface to be irradiated, 
resulting in 20 groups with $(\mathrm{n}=5)$ (Table 1$)$.

After light curing, specimens were stored dry at $37^{\circ} \mathrm{C}$ for $24 \mathrm{~h}$. For Knoop hardness measurements, the specimens were bisected longitudinally under water cooling with diamond saw (Extec model 12205, Extec Corp., Enfield, CT, USA). The exposed surfaces exhibiting the adhesive interface were sequentially polished under water cooling with 400-, 600- and 1200-grit SiC papers for 15, 30 and $60 \mathrm{~s}$, respectively, in a universal polishing machine (APL-4; Arotec).

\section{Knoop Hardness Measurements}

Indentation and microhardness measurements were performed in a microhardness tester (model HMV-2; Shimadzu, Tokyo, Japan). Three sequences of 3 indentations each ( $50 \mathrm{gf}$ during $15 \mathrm{~s}$ ) were performed to obtain 3 hardness values for each depth: $50 \mu \mathrm{m}, 400$ $\mu \mathrm{m}$ and $750 \mu \mathrm{m}$ from the interface between pre-cured resin disc and resin cement (Fig. 2).

A hardness mean value (dependent variable) was obtained for each depth in each specimen and the values were submitted to Split-plot 3-way ANOVA (composite

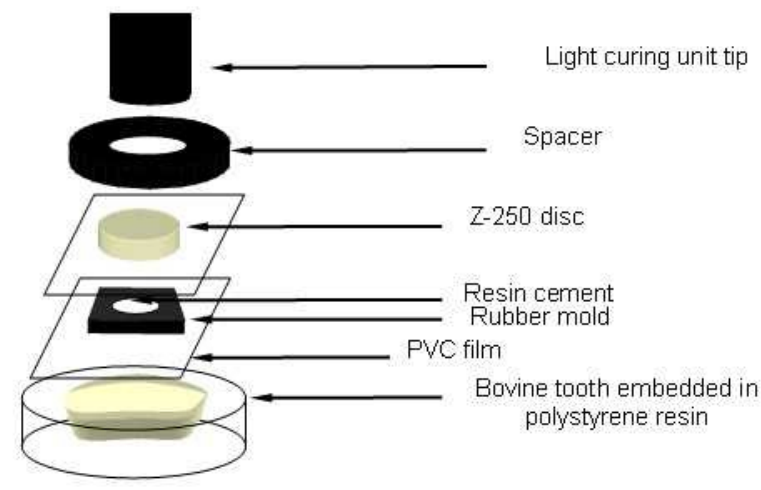

Figure 1. Schematic presentation of specimen preparation.

Table 1. Distribution of groups according to resin composite disc thickness and light-curing unit tip distance.

\begin{tabular}{cccccc}
\hline \multirow{2}{*}{$\begin{array}{c}\text { Light-curing unit tip } \\
\text { distance (mm) }\end{array}$} & \multicolumn{5}{c}{ Disc thickness (mm) } \\
\cline { 2 - 6 } & 2 & 3 & 4 & 5 & 0 \\
\hline 0 & $(0 / 2)$ & $(0 / 3)$ & $(0 / 4)$ & $(0 / 5)$ & $(0 / 0)$ \\
1 & $(1 / 2)$ & $(1 / 3)$ & $(1 / 4)$ & $(1 / 5)$ & $(1 / 0)$ \\
2 & $(0 / 4)$ & $(2 / 3)$ & $(2 / 4)$ & $(2 / 5)$ & $(2 / 0)$ \\
3 & $(3 / 2)$ & $(3 / 3)$ & $(3 / 4)$ & $(3 / 5)$ & $(3 / 0)$ \\
\hline
\end{tabular}

resin disc thickness $\mathrm{x}$ light-curing unit tip distance $\mathrm{x}$ polymerization depth). It was considered as factorial scheme the composite disk thickness and distance of light-curing unit tip as parcel and the depth as sub parcel. Tukey's post-hoc test for multiple comparisons was applied for comparison among groups. Significance was set at 5\% for both tests and statistical analyses were performed using SAS/lab software to test the assumptions and The SAS/STAT software to perform ANOVA and multiple comparisons test.

\section{RESULTS}

The polymerization depth presented statistically significant interaction with composite resin disc thickness and light-curing unit tip distance $(\mathrm{p}<0.05)$. The interaction between light-curing unit tip distance and composite disc thickness was not significant ( $p>0.05$ ). There was no significant interaction among the three factors ( $\mathrm{p}>0.05)$.

There was a significant decrease $(p<0.05)$ in hardness at the top of the resin cement layer with the increase in composite disc thickness when groups having 4-mm and 5-mm-thick pre-cured resin discs were compared to the direct light curing groups and groups with 2-and 3-mm-thick pre-cured resin discs. Specimens with indirect light-activation showed lower hardness when compared to the direct light curing groups at the center and bottom of the resin cement layer, regardless of the resin disc thickness. The bottom of the resin cement layer presented the lower hardness with the increase in thickness of the pre-cured resin disc. Higher hardness was observed at the center when compared to the values observed at the top, regardless of the thickness of the pre-cured composite resin disc (Fig. 3).

No decrease in hardness was observed when the distance between the light-curing unit tip and the

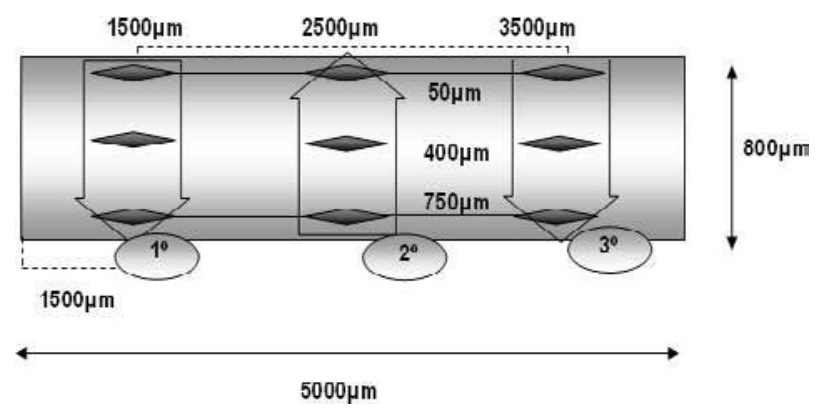

Figure 2. Schematic representation of indentation performed at the resin cement layer. 
composite surface was increased, except at the top of the resin cement layer, which presented the highest hardness value with direct light curing and the lowest with light-curing unit tip $1 \mathrm{~mm}$ distant from the resin surface. The hardness values obtained with the distance of 2 and $3 \mathrm{~mm}$ between the light-curing unit tip and the resin surface were similar to those obtained with direct light curing and when the light-curing unit tip was $1 \mathrm{~mm}$ distant. Regardless of the distance between the lightcuring unit tip and the resin cement, the bottom of the resin cement layer presented the lowest hardness values when compared to the center and top regions, and the highest values were observed at the center. The same was observed in all tested groups (Fig. 4).

\section{DISCUSSION}

An adequate polymerization is essential to ensure the best performance of resin cements, which is directly associated with the clinical success of materials. In addition, some factors can reduce the power density delivered to the luting agent during the cementation of indirect composite resin restoration. Among these factors, the influence of cavity depth and the distance between the light-curing unit tip and the resin cement surface were evaluated in this study.

The results of this study showed statistically significant differences in hardness at the top, center and bottom regions of resin cement layers light cured through different thickness of pre-cured composite resin discs (Fig. 3). A decrease in hardness was observed at the top of the resin cement layer specifically when groups

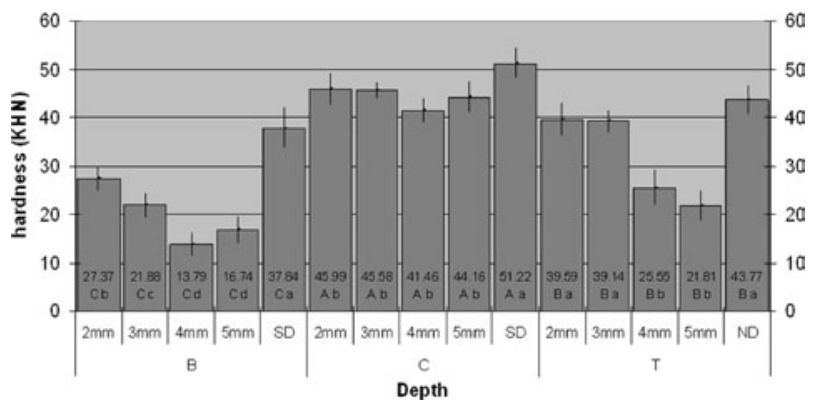

Figure 3. Bar graph showing Knoop hardness means for different combinations of resin cement depth - (top (T), center $(\mathrm{C})$ and bottom (B)) and thickness of pre-cured resin disc. Bars with same uppercase letter in each depth $(\mathrm{B}, \mathrm{C}$ and $\mathrm{T})$ indicate similar hardness values according to Tukey's test $(\alpha=0.05)$; Bars with same lowercase letter in each thickness $(\mathrm{mm})$ indicate similar hardness values according to Tukey's test $(\alpha=0.05)$. having 4-mm and 5-mm-thick pre-cured composite resin discs were compared to those with direct light curing and with 2-mm and 3-mm-thick composite discs, according to Pazin et al. (8). Moreover, hardness decreased at the center and bottom of the resin cement layer regardless of the resin disc thickness.

According to Moon et al. (13), the composite resin polymerization is proportional to the power density of the light reaching the resin surface. As light intensity decreases exponentially in function of the restoration thickness, less light penetration is expected when thicker restorations are used and consequently lower degree of conversion is observed in resin cements beneath such restorations (4). This fact results in negative effects on composite resin physical properties and on resin cements, as observed elsewhere (14).

In this current study, hardness values were lower at the top, center and bottom of the resin cement layer with the increase in resin disc thickness between the light source and the resin cement during light curing. These results can be associated with the low energy supplied to the resin cement to sensitize photoinitiators molecules, resulting in low degree of conversion and hardness (15). It can be speculated that the light transmittance obtained using 4-mm and 5-mm-thick composite resin discs was not adequate for suitable light activation of resin cement at the top of the resin cement layer and that chemical activation was responsible for the hardness values verified in these groups.

The hardness of the groups directly activated $(0 / 0),(1 / 0),(2 / 0)$ and $(3 / 0)$ was higher at the top of the resin cement layer than that of the groups having

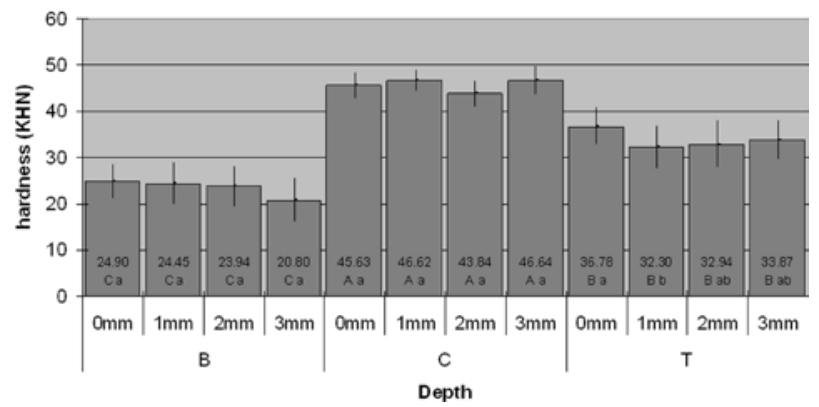

Figure 4. Bar graph showing Knoop hardness means for different combinations of resin cement polymerization depth (top (T), center (C) and bottom (B)) and light-curing unit tip distance. Bars with same lowercase letter in each depth (B, C and T) indicate similar hardness values according to Tukey's test $(\alpha=0.05)$; Bars with same lowercase letter in each light curing unit tip distance $(\mathrm{mm})$ indicate similar hardness values according to Tukey's test $(\alpha=0.05)$. 
4-mm and 5-mm-thick pre-cured resin discs and higher than the hardness at the center and bottom of the resin cement layer of groups with 2-, 3-, 4-, and 5 mm-thick pre-cured resin discs. These results corroborate with those of Warren (9) who observed higher hardness with direct light curing of resin cements when compared to the hardness obtained with indirect light curing. The author suggested that the exposure time of light should be increased for thicker restorations to promote similar hardness in comparison to that obtained with direct light curing. This longer light exposure could compensate for light attenuation by air, restoration opacity and thickness. It should be considered that the light exposure time recommended by manufacturers is optimum to obtain the proper hardness value of resin cement only with direct light curing (16).

Regarding resin cement polymerization depth, the top of the resin cement layer presented lower hardness values than the center regardless of the thickness of the resin disc or the distance between the curing unit tip and the resin cement layer (Figs. 3 and 4). It is possible that the composite resin disc load on the resin cement during specimen preparation and light activation lead inorganic fillers to concentrate at the center of the resin cement layer. Therefore, the resin monomer would emerge to the top and bottom regions and fillers concentration at center would lead to higher microhardness values. A previous study (17) has shown that the percentage of unreacted $\mathrm{C}-\mathrm{C}$ bonds is twice bigger at the surface in comparison to such percentage at the bulk of the resin material. Free radicals are three-dimensionally surrounded by reaction components in the bulk, while superficial free radicals react with others linearly at the composite surface.

The bottom region of the specimens obtained with indirect light activation presented the lowest hardness values compared to the other regions. It is possible that the self-curing mechanism was not capable of inducing suitable polymerization at deep areas (18). According to Pilo et al. (15), low degree of conversion and low hardness values can be attributed to poor light exposure, what can explain the influence of composite resin discs interposed between light-curing unit tip and resin cement on resin cement hardness values. Probably, the power density supplied for resin cement during light curing was inadequate to excite photoinitiators at deep areas because of light absorption and scraping by superficial areas (5). The reciprocity between exposure time and light intensity could be also applied to overcome the effects on polymerization depth, once such effects are related to energy supplied for activation (7).

The distance of the light-curing unit tip from the surface to be irradiated is another limitation factor to be considered for light transmittance. No significant difference in hardness at the center and bottom of the resin cement layer was observed with the increase in the distance between light-curing unit tip and the resin cement surface (Fig. 4). However, the top of the resin cement layer showed lower hardness when the light-curing unit tip was $1 \mathrm{~mm}$ distant from the resin cement layer. This finding corroborates those of Aquirar et al. (19), who observed a decrease in hardness with an increase in the distance of the light-curing unit tip from the resin surface. In addition, the composite resin thickness had an important role in the results of the present study.

Some authors have indicated light-curing units with a minimum light intensity of $300 \mathrm{~mW} / \mathrm{cm}^{2}$ for the photoactivation of resin restorative materials. The ISO 4049 standard does not have any recommendation about the minimum light intensity for photoactivation, but recommends that manufacturers' instructions should be followed on studies. The light intensity of the light-curing unit used in this study was $800 \mathrm{~mW} / \mathrm{cm}^{2}$, which is higher than minimum indicated in earlier studies. According to Rahiotis et al. (20), photoactivation with high intensity during the initial $15 \mathrm{~s}$ can lead to a fast polymerization of the superficial layer, changing its optical properties, what could explain the high variation in hardness values at the top of the resin cement layer.

Based on the results of this study and considering its limitations, it may be concluded that resin cement polymerization depth can be affected by the thickness of indirect composite restorations, and also by the distance between the light-curing unit tip and the surface to be irradiated. Clinically, an inadequate polymerization can lead to early degradation of the luting agent by hydrolysis, thus compromising the adhesive interface.

\section{RESUMO}

O estudo avaliou a profundidade de polimerização de um cimento resinoso dual, através da dureza Knoop (KHN), ativado em diferentes distâncias e espessuras de compósito resinoso. A dentina bovina foi planificada e embutida em resina, coberta com filme de PVC, onde um molde $(0,8 \mathrm{~mm} \times 5 \mathrm{~mm})$ sobreposto foi preenchido com cimento e coberto com outro filme de PVC. A fotoativação (40 s) foi realizada através de discos de compósito (2, 3, 4 ou $5 \mathrm{~mm}$-espessura) com a luz a $0,1,2$ ou $3 \mathrm{~mm}$ de distância da superfície do compósito. Após armazenagem, os espécimes foram seccionados e a KHN medida (superfície, centro e base). Os dados foram submetidos à ANOVA com parcelas subdivididas e teste 
de Tukey $(\alpha=0.05)$. A espessura do compósito diminuiu a dureza do cimento. $\mathrm{O}$ aumento da distância de fotoativação diminuiu a dureza na superfície do cimento. Espécimes mostraram menores valores de dureza na região de base e os maiores valores no centro. A dureza do cimento resinoso foi influenciada pela espessura da restauração indireta e pela distância entre a ponta da unidade fotoativadora e a superfície do cimento resinoso.

\section{ACKNOWLEDGEMENTS}

This study was partially supported by CAPES.

\section{REFERENCES}

1. Hooshmand T, Mahmoodi, Keshva A. Microhardness of a resin cement polymerized by light-emitting diode and halogen lights through ceramic. J Prosthodont 2009;18;411-416.

2. Fabianelli A, Goracci C, Bertelli E, Davidson CL, Ferrari M. A clinical trial of Empress II porcelain inlays luted to vital teeth with a dual-curing adhesive system and a self-curing resin cement. J Adhes Dent 2006;8:427-431.

3. Reges RV, Costa AR, Correr AB, Piva E, Puppin-Rontani RM, Sinhoreti MAC et al.. Effect of light-curing units, post-cured time and shade of resin cement on Knoop hardness. Braz Dent J 2009;20:410-413.

4. Daronch M, Miranda JrWG, Braga RR, Mirage. A Composite depth of cure using different light sources. J Dent Res 2000;79: 370.

5. Hansen EK, Asmussen E. Visible-light-curing units: Correlation between depth of cure and distance between exit window and resin surface. Acta Odontol Scand 1997;55:162-166.

6. Price RBT, Félix CA, Andreou P. Effect of resin composite and irradiation distance in the performance of curing lights. Biomater 2004;25:4465-4477.

7. Halvorson RH, Erickson RL, Davidson CL. Energy dependent polymerization of resin-based composite. Dent Mater 2002;18:463469.

8. Pazin MC, Moraes RR, Gonçalves LS, Borges GA, Sinhoreti MAC, Correr-Sobrinho L. Effects of ceramic thickness and curing unit on light transmission through leucite-reinforced material and polymerization of dual-cured luting agent. J Oral Sci 2008; 50:131-136.
9. Warren A. An investigation into the microhardness of a light cured composite when cured through varying thicknesses of porcelain. J Oral Rehabil 1990;17:327-334.

10. El-Bradawy WA, El-Mowafy OM. Chemical versus dual curing of resin inlay cements. J Prosthet Dent 1995;73:515-524.

11. Caldas DBM, Almeida JB, Correr-Sobrinho L, Sinhoreti MAC, Consani S. Influence of curing tip distance on resin composite Knoop hardness number, using three different light-curing units. Oper Dent 2003;28:315-320.

12. TangoRN, Sinhoreti MAC, Correr AB, Correr-Sobrinho L, Henriques GEP. Effect of light-curing method and cement activation mode on resin cement knoop hardness. J Prosthodont 2007; 16:480-484.

13. Moon HJ, Lee YK, Lim BS, Kim CW. Effects of various light curing methods on the leachability of uncured substances and hardness of a composite resin. J Oral Rehabil 2004;31:258-264.

14. Rasetto FH, Driscoll CF, von Fraunhofer JA. Effect of light source and time on the polymerization of resin cement trough ceramic veneers. J Prosthodont 2001;10:133-139.

15. Pilo R, Oelgiesser D, Cardash HS. A survey of output intensity and potential for depth of cure among light-curing units in clinical use. J Dent 1999;27:235-241.

16. Hasegawa EA, Boyer DB, Chan DC. Hardening of dual-cured cements under composite resin inlays. J Prosthet Dent 1991;66:187192.

17. Hofmann N, Hugo B, Schubert K, Klaiber B. Comparison between a plasma arc light source and conventional halogen curing units regarding flexural strength, modulus and hardness of photoactivated resin composites. Clin Oral Invest 2000;4:140-147.

18. Sigemori RM, Reis A, Gianini M, Paulillo LAMS. Curing depth of a resin-modified glass ionomer and two resin-based luting agents. Oper Dent 2005;30:185-189.

19. Aquirar FH, Oliveira TR, Lima DA, Ambrosano G, Lovadino JR. Microhardness of different thicknesses of resin composite polymerized by conventional photocuring at different distances. Gen Dent 2008;56:144-148.

20. Rahiotis C, Kakaboura A, Loukidis M, Vougiouklakis G. Curing efficiency of various types of light-curing units. Eur J Oral Sci 2004;112:89-94.

Accepted April 15, 2010 